\title{
Meaningful use: an electronic medical record tool for cerebrospinal fluid shunt history
}

\author{
Lance S. Governale, MD, ${ }^{1,2}$ and Jeffrey M. Hoffman, MD ${ }^{3,4}$ \\ Divisions of ${ }^{1}$ Pediatric Neurosurgery, ${ }^{3}$ Emergency Medicine, and ${ }^{4}$ Chief Medical Information Officer, Nationwide Children's \\ Hospital; and ${ }^{2}$ Department of Neurosurgery, The Ohio State University, Columbus, Ohio
}

\begin{abstract}
The care of patients with shunted hydrocephalus can be complicated. The best assessment is provided when all data are available to the neurosurgery practitioner. However, data can be time-consuming to gather, especially in the setting of a busy practice, a trainee environment with duty-hour restrictions, and an electronic medical record (EMR) not specifically designed for the needs of subspecialists. For these reasons, the complete clinical picture, especially the historical component, is sometimes not assembled.

To address these shortcomings, the authors created a patient-level electronic CSF shunt history tool that leverages the power of the EMR concordant with the United States Centers for Medicare and Medicaid Services meaningful use principles. It is immediately available within the EMR for all users in all patient care contexts (e.g., outpatient, inpatient, perioperative, emergency, and remote access), centrally located, and designed to capture the vast range of circumstances inherent to the hydrocephalus population. Essential shunt data can be rapidly acquired and, as such, may decrease the likelihood of error in diagnosis and/or treatment. The tool also has the potential to aid the practicing neurosurgeon from clinical, quality improvement, and research standpoints. The authors have endeavored to describe this tool in a manner that would allow an interested neurosurgeon to share this publication with health information technology professionals to facilitate the development of a similar tool within their institution's own EMR platform.
\end{abstract}

https://thejns.org/doi/abs/10.3171/2016.11.PEDS16381

KEY WORDS cerebrospinal fluid shunt; ventriculoperitoneal shunt; electronic medical record; pediatric; neurosurgery; hydrocephalus

$\mathrm{T}$ HE evaluation of patients with shunted hydrocephalus for shunt malfunction or infection can be complicated. The best assessment is provided when all data are available to the neurosurgery practitioner. However, data can be time-consuming to gather, especially in the setting of a busy practice, a trainee environment with duty hour-restrictions, and an electronic medical record (EMR) not specifically designed for the needs of subspecialists. As such, the complete clinical picture, especially the historical component, is sometimes not assembled. While this may suffice for straightforward shunt evaluations, a typical pediatric neurosurgical practice is replete with patients with complex shunt systems and histories.

Increasingly, government regulations associated with financial incentives and penalties are impacting clinical practice. Over the past several years, the United States Centers for Medicare and Medicaid Services introduced the meaningful use program ${ }^{1,9}$ with stated goals to use
EMR technology to "improve quality, safety, efficiency, and reduce health disparities; engage patients and family; improve care coordination, and population and public health; and maintain privacy and security of patient health information." ${ }^{5}$ The program is intended to result in "better clinical outcomes, improved population health outcomes, increased transparency and efficiency, empowered individuals, and more robust research data on health systems." ${ }^{5}$ Compliance with meaningful use was initially driven by incentive programs and later by financial penalties for institutions not meeting specific measures. ${ }^{2}$ Smaller subspecialties, such as neurosurgery, have not been overall positively impacted by the changes health care organizations have had to make in deploying and configuring EMR systems to meet meaningful use requirements.

To simplify the acquisition of essential shunt data and to make them immediately available within the EMR for all users in all patient care contexts (e.g., outpatient, in-

ABBREVIATIONS EMR = electronic medical record; IVH = intraventricular hemorrhage; $\mathrm{QI}$ = quality improvement.

SUBMITTED July 3, 2016. ACCEPTED November 29, 2016.

INCLUDE WHEN CITING Published online February 10, 2017; DOI: 10.3171/2016.11.PEDS16381. 
TABLE 1. Data contained within the EMR shunt tool

\begin{tabular}{|c|c|}
\hline Data Category & Data Field \\
\hline \multirow[t]{3}{*}{ General Information } & Etiology of hydrocephalus \\
\hline & Usual malfunction symptoms \\
\hline & Ventricles enlarge $\mathrm{w} /$ malfunction or not \\
\hline \multirow[t]{14}{*}{ Active CSF Shunts } & Initial placement date \\
\hline & Proximal catheter location \\
\hline & Distal catheter location \\
\hline & Tube travels on It or rt side of body \\
\hline & Valve type \\
\hline & Valve setting, if adjustable \\
\hline & Intentional or unintentional valve setting \\
\hline & Antisiphon device type \\
\hline & Antisiphon device setting, if adjustable \\
\hline & Tappable or nontappable \\
\hline & Suspected or confirmed nonfunctional \\
\hline & Functionality determined by whom \\
\hline & Last revision date \\
\hline & Other comments \\
\hline Inactive CSF Shunts & Removal date \\
\hline \multirow[t]{6}{*}{ CSF Shunt Procedures } & Procedure date \\
\hline & Procedure time \\
\hline & Procedure title \\
\hline & Surgeon \\
\hline & Assistants \\
\hline & Operative report link \\
\hline \multirow{4}{*}{$\begin{array}{l}\text { Audit Information (log of } \\
\text { changes to any data field) }\end{array}$} & Which data field was changed \\
\hline & When it was changed \\
\hline & Who changed it \\
\hline & What was the new value \\
\hline
\end{tabular}

For a complete listing of all choices within each data field, please see Appendix 1.

patient, perioperative, emergency, and remote access) in a centralized location, we created a patient-level electronic tool that leverages the power of the EMR concordant with meaningful use principles to aid the practicing neurosurgeon from clinical, quality improvement (QI), and research standpoints.

\section{Methods \\ Tool Content}

The shunt history is presented as an electronic document consisting of 5 sections: 1) "General Information" related to the patient's hydrocephalus; 2) "Active CSF Shunts" providing information about the current implanted shunt system(s); 3) "Inactive CSF Shunts" archiving shunt systems that have since been removed; 4) "CSF Shunt Procedures" listing the patient's hydrocephalus operative history; and 5) "Audit Information," which tracks changes to the data stored in the tool. Table 1 details the data fields available in each section. Data for the General Information and Active CSF Shunts sections are manually entered, while data for the remaining 3 sections are automatically obtained from elsewhere within the EMR. The tool allows users to input some or all information, with only a minimum of information being required.

All information related to shunt hardware and settings can be accommodated within the tool. Multiple active shunts can be represented separately and discretely with each shunt defined as 1 valve. For example, a shunt system with 2 proximal catheters connected above a single valve would be listed as 1 shunt with 2 proximal catheters associated with it. The tube travel field is designed to capture on which side of the neck the tube is located for a ventricular shunt, but it can also be used to note which side of the body a lumboperitoneal shunt tube is located. The data fields are designed to allow the user to capture a variety of events. For example, if a shunt valve is found to be at the incorrect setting (which may be useful information later when interpreting scans or symptoms), this can be documented using the "unintentional" valve setting field. To provide maximum documentation flexibility, additional comments can be added to any data. Appendix 1 contains a full listing of the choices available for each data field. Note that each option for valve type and setting displays its opening pressure according to the manufacturer's

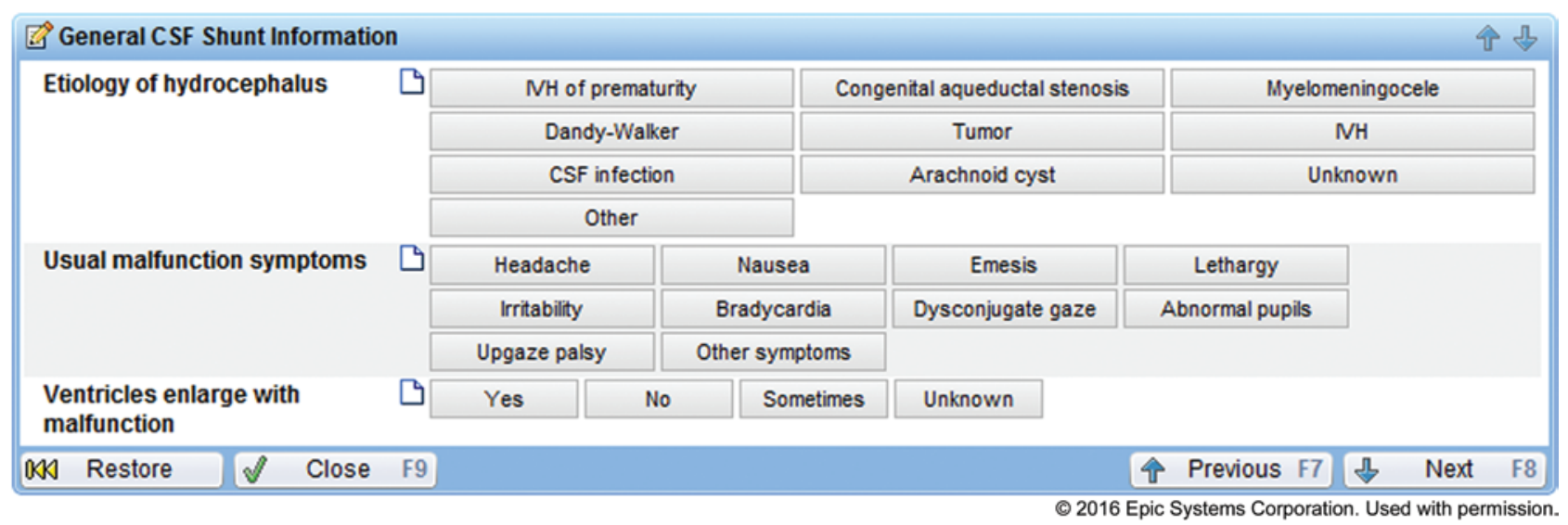

FIG. 1. Data entry module for the General Information section. Copyright Epic Systems Corp. Published with permission. Figure is available in color online only. 


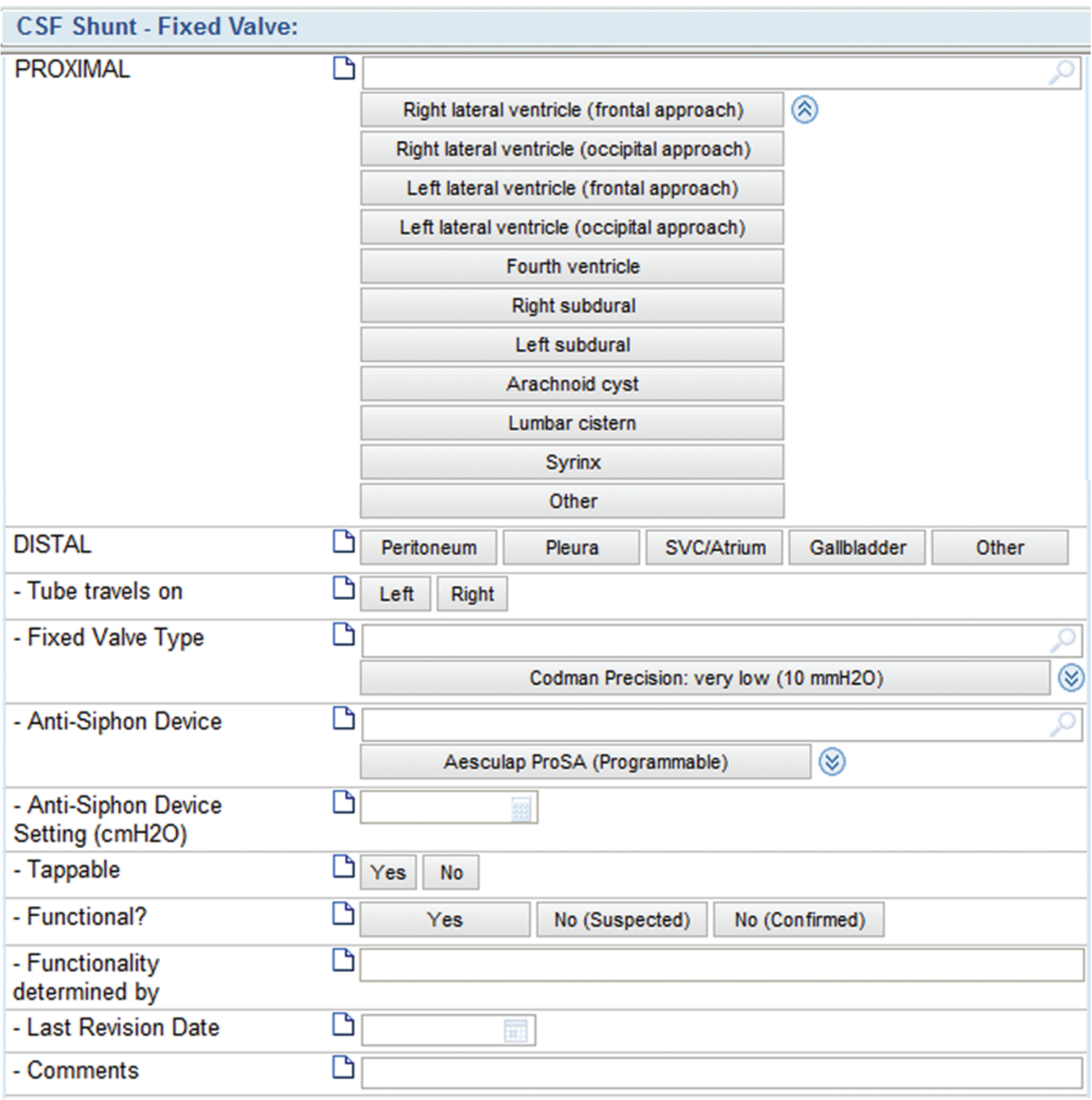

(C) 2016 Epic Systems Corporation. Used with permission.

FIG. 2. Data entry module for the Active CSF Shunts section. The drop-down list for the proximal catheter has been expanded. Copyright Epic Systems Corp. Published with permission. Figure is available in color online only.

literature. This form of integrated decision support further helps the clinician manage the patient's shunt by avoiding the need to reference information from other sources.

The CSF Shunt Procedures section allows users to visualize a chronological list of all hydrocephalus-related operative procedures performed to date, including endoscopy. This information is automatically populated from the integrated perioperative information system by filtering for the Current Procedural Terminology codes specified in Appendix 1. In addition to the date and type of procedure performed, the surgeon's operative note for each case is viewable by a quick hyperlink from within the tool.

\section{Tool Design}

The shunt history documentation and summary tool was developed using a feature available within our existing Epic EMR platform (Epic Systems Corp.) designed to document indwelling drain catheters. This type of information is captured during the course of care within the ambulatory, inpatient, and/or perioperative setting but then persists across encounters and is made available to 
TABLE 2. Baseline hydrocephalus characteristics of patients with data in the EMR shunt tool at our institution

\begin{tabular}{|c|c|}
\hline Variable (no. of patients w/ data) & Frequency (\%) \\
\hline \multicolumn{2}{|l|}{ Etiology of hydrocephalus $(n=255)^{*}$} \\
\hline IVH of prematurity & $70(27.5)$ \\
\hline Congenital aqueductal stenosis & $26(10.2)$ \\
\hline Myelomeningocele & $52(20.4)$ \\
\hline Dandy-Walker & $2(0.4)$ \\
\hline Tumor & $15(5.9)$ \\
\hline IVH & $14(5.5)$ \\
\hline CSF infection & $5(2.0)$ \\
\hline Arachnoid cyst & $21(8.2)$ \\
\hline Unknown & $16(6.3)$ \\
\hline Other & $39(15.3)$ \\
\hline \multicolumn{2}{|l|}{ Usual malfunction symptoms $(n=113)^{*}$} \\
\hline Headache & $62(54.9)$ \\
\hline Nausea & $28(24.8)$ \\
\hline Emesis & $62(54.9)$ \\
\hline Lethargy & $45(39.8)$ \\
\hline Irritability & $29(25.7)$ \\
\hline Bradycardia & $9(8.0)$ \\
\hline Dysconjugate gaze & $5(4.4)$ \\
\hline Abnormal pupils & $0(0.0)$ \\
\hline Upgaze palsy & $5(4.4)$ \\
\hline Other & $32(28.3)$ \\
\hline \multicolumn{2}{|c|}{ Ventricles enlarge $w /$ malfunction? $(n=118)$} \\
\hline Yes & $103(87.3)$ \\
\hline No & $10(8.5)$ \\
\hline Sometimes & $5(4.2)$ \\
\hline
\end{tabular}

* As each patient may have more than 1 selection, the total is greater than $100 \%$.

all users at all times within the patient's longitudinal electronic health record. Read access and write access to the tool can be specified according to user role or group, if desired. The user interface was designed primarily with buttons and selection lists for ease of use, to minimize the burden of data entry, and to capture discrete data elements, which allows for subsequent query (Figs. 1 and 2). To accommodate maximum documentation flexibility, most data fields allow for multiple options to be selected if applicable (for example, more than 1 ventricular catheter in a single shunt system). The CSF Shunt Procedures section automatically obtains relevant surgical case information from our integrated operating room information system, which we began using at our institution in November 2014. This is noted for the user in the shunt tool in case earlier procedure documentation is being sought.

\section{Tool Use}

The decision regarding who updates the data in the shunt history tool and when would depend on institutionspecific workflows. At our institution, the information is updated by an intake nurse during clinic visits and by the inpatient nurse practitioner team on hospital discharge. A
TABLE 3. Baseline shunt characteristics of patients with data in the EMR shunt tool at our institution

\begin{tabular}{|c|c|}
\hline Variable (patients w/ data) & Frequency $(\%)$ \\
\hline \multicolumn{2}{|l|}{ No. of proximal catheters $(n=533)$} \\
\hline 1 & $480(90.1)$ \\
\hline 2 & $43(8.1)$ \\
\hline 3 & $10(1.9)$ \\
\hline \multicolumn{2}{|l|}{ Proximal catheter location $(n=596)$} \\
\hline Rt lat ventricle, frontal approach & $138(23.2)$ \\
\hline Rt lat ventricle, occipital approach & $292(49.0)$ \\
\hline Lt lat ventricle, frontal approach & $0(0.0)$ \\
\hline Lt lat ventricle, occipital approach & $100(16.8)$ \\
\hline 4th ventricle & $8(1.3)$ \\
\hline Subdural & $12(2.0)$ \\
\hline Arachnoid cyst & $24(4.0)$ \\
\hline Lumbar cistern & $1(0.2)$ \\
\hline Syrinx & $0(0.0)$ \\
\hline Other & $21(3.5)$ \\
\hline \multicolumn{2}{|l|}{ Distal catheter location $(n=583$ ) } \\
\hline Peritoneum & $558(95.7)$ \\
\hline Pleura & $3(0.5)$ \\
\hline SVC/atrium & $15(2.6)$ \\
\hline Gallbladder & $7(1.2)$ \\
\hline \multicolumn{2}{|l|}{ Side of body the tube travels $(n=551)$} \\
\hline Lt & $101(18.3)$ \\
\hline $\mathrm{Rt}$ & $450(81.7)$ \\
\hline \multicolumn{2}{|l|}{ Valve type $(n=542)$} \\
\hline Fixed pressure & $369(68.1)$ \\
\hline Programmable & $173(31.9)$ \\
\hline \multicolumn{2}{|l|}{ Tappable or nontappable $(n=183)$} \\
\hline Tappable & $155(84.7)$ \\
\hline Nontappable & $28(15.3)$ \\
\hline \multicolumn{2}{|l|}{ Nonfunctional $(n=597)$} \\
\hline Suspected & $12(2.0)$ \\
\hline Confirmed & $3(0.5)$ \\
\hline
\end{tabular}

SVC = superior vena cava.

trainee may update the documentation tool during evaluations in the Emergency Department if he or she has gathered information not already present and has time to enter it. As one may expect, trainee compliance with maintaining the tool is variable. At first glance, the tool may appear complicated and burdensome to complete. However, the minimum basic information required to make the tool a useful adjunct to patient care (proximal catheter location, valve type, and distal catheter location) can be entered rapidly and easily once familiarity with the user interface and layout is acquired. The remaining information, although valuable to document and capture, is optional.

We began to use the shunt history tool at our institution in July 2014. The CSF Shunt Procedures section was added after the operating room transitioned to an integrated information system in November 2014. As of October 2016, 572 patients with 597 active shunts have had manual 
General Information

Etiology of hydrocephalus: IVH

Usual malfunction symptoms: Headache, Lethargy, Irritability (Comment: Aug 26 2015: "High pitched cry", intermittent lethargy)

Ventricles enlarge with malfunction: Yes (Comment: Eg Aug 262015 )

Patient Lines/Drains/Airways Status

Active CSF Shunts

Placement date: -2 Placement time:

Name:

(supine 35-55

Placement date: $\quad$ Placement time: $\quad$ Sie:

Site: $\quad$ Days: $\quad$ Additional Info

approach)

DISTAL: Peritoneum

- Tube travels on: Right

- Fixed Valve Type: Medtronic Delta: 10 (supine 35-55 mmH2O, standing 50-70 mmH2O)

- Tappable: Yes

- Last Revision Date: 12/05/15

Inactive CSF Shunts

CSF Shunt Procedures Performed/Scheduled at NCH since 11/1/2014**

Past Procedures (11/1/2014 to Today)

Date Time

58/15/2015 $\quad 1510$

Procedures

Ventricular Peritoneal Shunt Exploration And Revision

Providers

Surgeon 1

Assistant 2

$\begin{array}{llll}\text { 512/5/2015 } & 1040 & \text { Revision Vp Shunt } & \text { Surgeon } 1\end{array}$

Assistant 1

$\begin{array}{ll}\text { Location } & \text { Status } \\ \text { Main OR } & \text { Complete }\end{array}$

Main OR

Complete

**For CSF Shunt Procedures Performed Prior to 11/1/2014, please refer to the relevant Operative notes in Chart Review.

2016 Epic Systems Corporation. Used with permission.

FIG. 3. The CSF shunt history for a 5-year-old boy with a relatively standard shunt system that includes a fixed pressure valve. All of the General Information section data are present. The exact procedure dates as well as the names of the surgeons and assistants have been changed for privacy reasons. For the same reasons, the patient's age, name, medical record number, and birthdate have been cropped out of the screenshot image. Copyright Epic Systems Corp. Published with permission. Figure is available in color online only.

data entered into the system. A quick query of the data revealed the baseline hydrocephalus and shunt characteristics of our patient population as shown in Tables 2 and 3.

Although we have not experienced any issues with the tool, users must always remain vigilant regarding data validity. The automatically obtained data, primarily in the
CSF Shunt Procedures section, are robust since these data are generated from a comprehensive list of hydrocephalus Current Procedural Terminology codes. It would be rare for a nonhydrocephalus code to be assigned to a hydrocephalus procedure. The manual entry fields require more care. We have found that the comment functionality has

General Information

Etiology of hydrocephalus: Myelomeningocele

Patient Lines/Drains/Airways Status

Active CSF Shunts

Name:

CSF Shunt - Programmable Valve: Medtronic

Strata II set to 1.0 (supine $35-55 \mathrm{mmH} 2 \mathrm{O}$,

standing 50-70 $\mathrm{mmH} 2 \mathrm{O}$ )

Placement date:

Placement time:

Site: approach)
Additional Info

DISTAL: Peritoneum

- Tube travels on: Right

- Valve: set to 1.0 (supine 35-55 mmH2O, standing 50-70 mmH2O) Re-set to performance level 1.0 after today's MR [1]

- Tappable: Yes

Inactive CSF Shunts

\begin{tabular}{|c|c|c|c|c|}
\hline \multicolumn{5}{|c|}{ 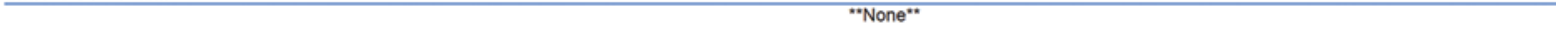 } \\
\hline \multicolumn{5}{|c|}{ Audit Information } \\
\hline Ref \# & Row Name & Time Recorded & Value & User \\
\hline \multirow[t]{5}{*}{1} & - Valve & $07 / 16 / 151525$ & $\begin{array}{l}\text { set to } 1.0 \text { (supine } 35-55 \mathrm{mmH} 2 \mathrm{O} \text {, standing } 50-70 \mathrm{mmH} 2 \mathrm{O} \text { ) Re-set to } \\
\text { performance level } 1.0 \text { after todays } \mathrm{MR}\end{array}$ & RC \\
\hline & & $09 / 14 / 141505$ & $\begin{array}{l}\text { set to } 1.0 \text { (supine } 35-55 \mathrm{mmH} 2 \mathrm{O} \text {, standing } 50-70 \mathrm{mmH} 2 \mathrm{O} \text { ) Reset to } 1.0 \text { after } \\
\text { MRI today }\end{array}$ & LG \\
\hline & & $09 / 14 / 141433$ & $\begin{array}{l}\text { set to } 1.0 \text { (supine } 35-55 \mathrm{mmH} 2 \mathrm{O} \text {, standing } 50-70 \mathrm{mmH} 2 \mathrm{O} \text { ) Reportodly roset } \\
\text { to } 1.0 \text { in ER July } 2014\end{array}$ & LG \\
\hline & & $09 / 14 / 141426$ & $\begin{array}{l}\text { set to } 1.5 \text { (supine } 70-90 \mathrm{mmH} 2 \mathrm{O} \text {, standing } 85-105 \mathrm{mmH} 2 \mathrm{O} \text { ) Raised from } 1.0 \\
\text { to } 1.5 \text { on May } 272014\end{array}$ & LG \\
\hline & & $09 / 14 / 141420$ & set to 1.0 (supine $35-55 \mathrm{mmH} 2 \mathrm{O}$, standing $50-70 \mathrm{mmH} 2 \mathrm{O}$ ) & LG \\
\hline
\end{tabular}

CSF Shunt Procedures Performed/Scheduled at NCH since 11/1/2014*

Past Procedures (11/1/2014 to Today)

$\begin{array}{ll}\text { Date } & \text { Time } \\ 53 / 15 / 2015 & 0930 \\ & \\ 55 / 2 / 2015 & 0730\end{array}$
Procedures
Revision Of Right Occipital Ventriculoperitoneal Shunt

Revision Vp Shunt

Providers
Surgeon 1
Assistant 1

Surgeon 1
Assistant 1

*For CSF Shunt Procedures Performed Prior to 11/1/2014, please refer to the relevant Operative notes in Chart Review.

FIG. 4. The CSF shunt history for a 3-year-old girl whose shunt valve is adjustable. Note the valve settings over time in the Audit Information section. The exact procedure dates as well as the names of the surgeons and assistants have been changed for privacy reasons. For the same reasons, the patient's age, name, medical record number, and birthdate have been cropped out of the screenshot image. Copyright Epic Systems Corp. Published with permission. Figure is available in color online only. 


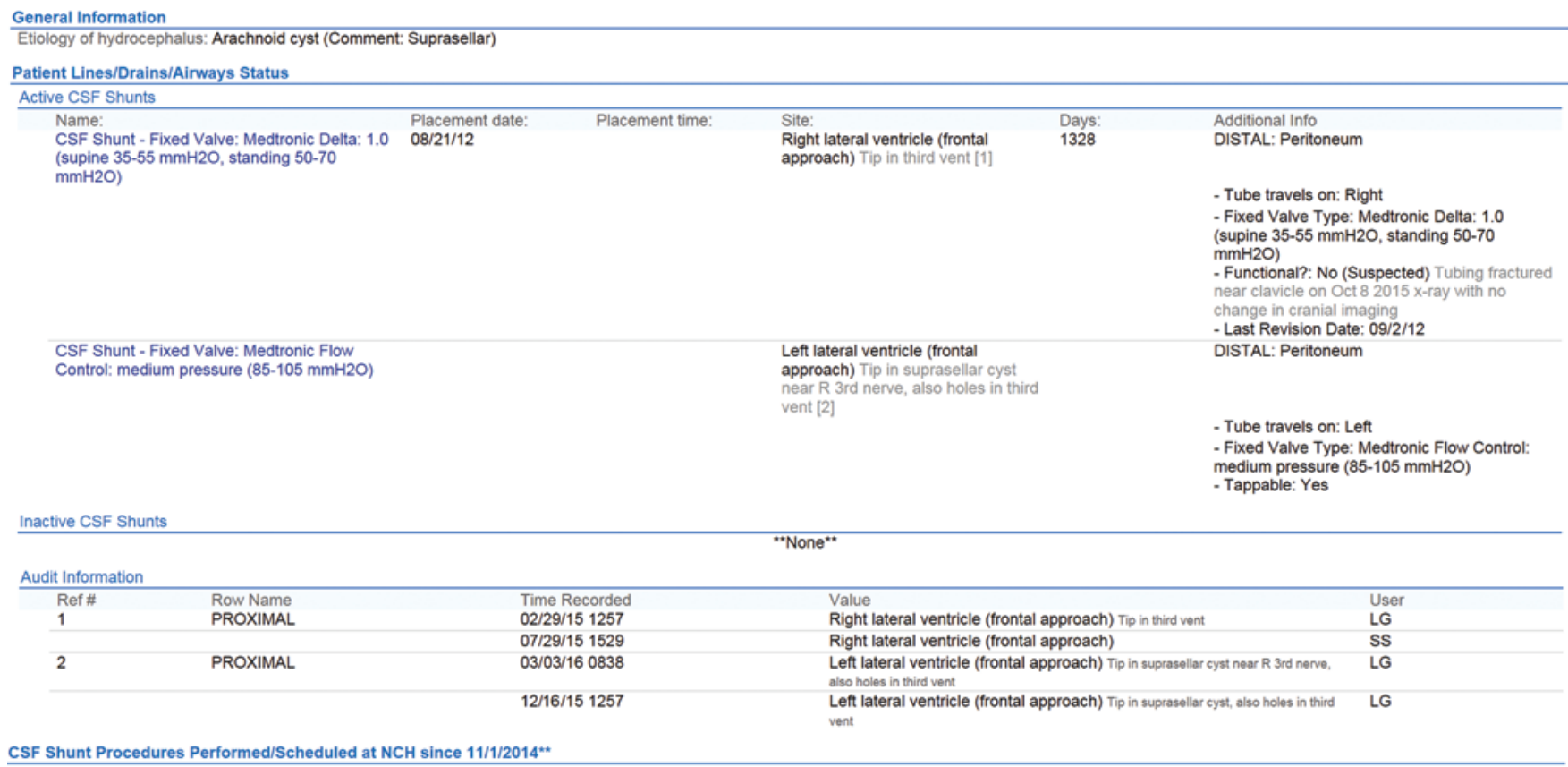

**For CSF Shunt Procedures Performed Prior to 11/1/2014, please refer to the relevant Operative notes in Chart Review.

๑ 2016 Epic Systems Corporation. Used with permission

FIG. 5. The CSF shunt history for a 5-year-old boy with a complex shunt system including 2 shunts. One shunt has a ventricular catheter that enters from a left frontal approach, travels through the left foramen of Monro, and ends with drainage holes in a suprasellar arachnoid cyst and in the third ventricle. The other shunt is suspected to be nonfunctional since prior radiographs showed fractured tubing without symptoms or change in cranial imaging. The ability to rapidly discern which system is thought to be functional may help to decrease the chance for error in an emergency situation. The exact procedure dates as well as the names of the surgeons and assistants have been changed for privacy reasons. For the same reasons, the patient's age, name, medical record number, and birthdate have been cropped out of the screenshot image. Copyright Epic Systems Corp. Published with permission. Figure is available in color online only.

helped in this endeavor. For example, if it is reported that a patient's ventricles increased in size with a shunt malfunction, it is prudent to add a comment with the date of the malfunction imaging scan. The next user can then quickly verify by viewing the scan without sorting through a long list of studies.

The issue of shunt functionality also requires specificity of documentation. Most neurosurgeons are aware that a fractured shunt can continue to function by draining through the fibrous tract that the body forms around it. It is difficult to determine with certainty that a shunt is nonfunctional; this usually requires an operative exploration or a shunt ligation. The latter, definitive scenario would be captured using the confirmed nonfunctional button. Instances of less certainty, such as fractured shunt tubing, would be noted using the suspected nonfunctional button. When using either of these buttons, we typically add comments listing the evidence for our conclusion.

The value of the tool may be augmented by various information output methods. In addition to viewing the information within the EMR online report, it can be automatically added to progress notes, if desired, using a documentation macro. Furthermore, storing data discretely within the EMR permits information sharing with other institutions via health information exchanges and with patients and families through online patient portals. We are actively exploring these information-sharing options as they may greatly aid in the care of a patient who presents to an institution other than his or her usual one.

\section{Case Examples}

Figure 3 shows the CSF shunt history tool for a 5-yearold boy with a relatively standard shunt system that includes a fixed pressure valve. All of the General Information section data are present. Figure 4 displays the tool for a 3-year-old girl whose shunt valve is adjustable. Note the valve settings over time in the Audit Information section. Figure 5 is from a 5-year-old boy with a complex shunt system including 2 shunts. One shunt has a ventricular catheter that enters from a left frontal approach, travels through the left foramen of Monro, and ends with drainage holes in a suprasellar arachnoid cyst and in the third ventricle. The other shunt is suspected to be nonfunctional since prior radiographs showed fractured tubing without symptoms or change in cranial imaging. The ability to rapidly discern which system is thought to be functional may help to decrease the chance for error in an emergency situation. Figure 6 is from a 12-month-old girl with multiloculated hydrocephalus due to intraventricular hemorrhage (IVH) of prematurity. She has a complex system consisting of 2 shunts, one of which has 2 ventricular catheters. She also has an extensive procedure history, including multiple endoscopic fenestrations. Having all of her shunt-related information in one place helps to elucidate her history for 


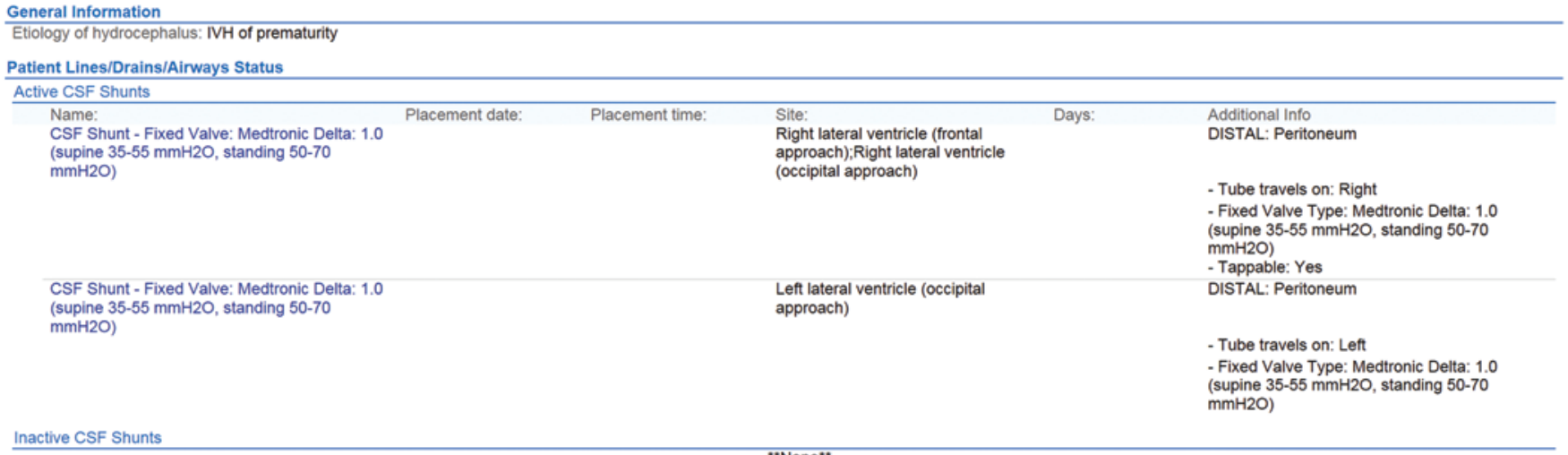

CSF Shunt Procedures Performed/Scheduled at NCH since 11/1/2014**

\begin{tabular}{|c|c|c|c|c|c|}
\hline \multicolumn{6}{|c|}{ Past Procedures (11/1/2014 to Today) } \\
\hline Date & Time & Procedures & Providers & Location & Status \\
\hline א3/18/2015 & 1430 & Placement Of Ventriculosubgaleal Shunt & $\begin{array}{l}\text { Surgeon } 1 \\
\text { Assistant } 1\end{array}$ & Main OR & Complete \\
\hline \$4/1/2015 & 0800 & Wash Out Of A Vsgs Shunt & Surgeon 1 & Main OR & Complete \\
\hline $55 / 2 / 2015$ & & Ventricular Peritoneal Shunt Insertion & Surgeon 1 & Main OR & Canceled \\
\hline $55 / 15 / 2015$ & 0900 & Ventricular Peritoneal Shunt Insertion & $\begin{array}{l}\text { Surgeon } 1 \\
\text { Assistant } 1\end{array}$ & Main OR & Complete \\
\hline $56 / 14 / 2015$ & 1630 & Left Endosopic Fenestration Of Cyst & $\begin{array}{l}\text { Surgeon } 1 \\
\text { Assistant } 1 \\
\text { Assistant } 2 \\
\text { Assistant } 3\end{array}$ & Main OR & Complete \\
\hline 58/2/2015 & 1600 & $\begin{array}{l}\text { Revision Vp Shunt } \\
\text { Endoscopic Fenestration Of Intraventricular Cysts }\end{array}$ & $\begin{array}{l}\text { Surgeon } 1 \\
\text { Assistant } 1 \\
\text { Assistant } 2\end{array}$ & Main OR & Complete \\
\hline 59/13/2015 & 1100 & $\begin{array}{l}\text { Right Frontal Endoscopic Cyst Fenestration, Temporal Cyst } \\
\text { Catheter Placement And Right Occipital Shunt Exploration And } \\
\text { Revision }\end{array}$ & $\begin{array}{l}\text { Surgeon } 1 \\
\text { Assistant } 1 \\
\text { Assistant } 2\end{array}$ & Main OR & Complete \\
\hline \$9/2/2015 & 1040 & $\begin{array}{l}\text { Left Endoscopic Fenestration Of Cyst With Placement Of } \\
\text { Ventriculoperitoneal Shunt }\end{array}$ & $\begin{array}{l}\text { Surgeon } 1 \\
\text { Assistant } 1\end{array}$ & Main OR & Complete \\
\hline $511 / 8 / 2015$ & 1510 & $\begin{array}{l}\text { Left Occipital Endoscopic Fenestration Of Cyst } \\
\text { Revision Left Occipital Ventriculoperitoneal Shunt }\end{array}$ & $\begin{array}{l}\text { Surgeon } 1 \\
\text { Assistant } 1\end{array}$ & Main OR & Complete \\
\hline $51 / 24 / 2016$ & 1700 & $\begin{array}{l}\text { I\&D Left Clavicle Fluid Collection } \\
\text { Externalization Of Left Vp Shunt }\end{array}$ & $\begin{array}{l}\text { Surgeon } 1 \\
\text { Assistant } 1\end{array}$ & Main OR & Complete \\
\hline \$1/28/2016 & 0950 & $\begin{array}{l}\text { Removal External Ventricular Device And Implantation Of Left } \\
\text { Ventriculoperitoneal Shunt System } \\
\text { Placement Of Anterior Distal Ventriculoperitoneal Shunt Tubing }\end{array}$ & $\begin{array}{l}\text { Surgeon } 1 \\
\text { Assistant } 1 \\
\text { Assistant } 2\end{array}$ & Main OR & Complete \\
\hline
\end{tabular}

*For CSF Shunt Procedures Performed Prior to 11/1/2014, please refer to the relevant Operative notes in Chart Review.

술 2016 Epic Systems Corporation. Used with permission.

FIG. 6. The CSF shunt history tool for a 12-month-old girl with multiloculated hydrocephalus due to IVH of prematurity. She has a complex system consisting of 2 shunts, one of which has 2 ventricular catheters. She also has an extensive procedure history, including multiple endoscopic fenestrations. Having all of her shunt-related information in one place helps to elucidate her history for providers who may be new to her hydrocephalus care, such as in an on-call coverage situation. This may lessen the chance for error. The exact procedure dates as well as the names of the surgeons and assistants have been changed for privacy reasons. For the same reasons, the patient's age, name, medical record number, and birthdate have been cropped out of the screenshot image. Copyright Epic Systems Corp. Published with permission. Figure is available in color online only.

providers who may be new to her hydrocephalus care, such as in an on-call coverage situation. This may lessen the chance for error.

\section{Discussion}

The care of patients with shunted hydrocephalus can be complicated. The best assessment is provided when all data are available to the neurosurgery practitioner. We have created a cross-encounter shunt history tool available in the EMR that leverages a combination of curated data entry by clinicians and automated display of existing relevant information. It is immediately available within the EMR for all users in all contexts of patient care (e.g., outpatient, inpatient, perioperative, emergency, and remote access), is centrally located, and is designed to capture the vast range of circumstances inherent to the hydrocephalus population. At the same time, the tool allows for discrete data capture to enable subsequent query and provides a flexible combination of quick entry buttons and free text comment fields. With this tool, vital patient data can be rapidly accessed in times of emergency and is presented efficiently during on-call coverage. These features provide maximum benefit to busy practitioners and hours-restricted trainees.

In addition to clinical value, the CSF shunt history tool has potential safety, QI, and research value. From a quality and safety standpoint, ensuring that all relevant data are available in a timely manner may decrease the chance for error in diagnosis and/or treatment. The tool's discrete data capture design allows it to serve as a data source for both QI and research investigation. Write access control aids in ensuring data accuracy, while read access control helps to ensure that the data are interpreted by experienced neurosurgical practitioners. Although the timing of the tool's launch precluded a pre- and postimplementation quality metric comparison at our institution, this could be examined in the future if other institution(s) and/or research consortia adopt the tool.

We designed and built our tool using functionality available within the Epic EMR platform; however, we have en- 
deavored to describe it in a manner that would allow interested neurosurgeons to share this publication with health information technology professionals at their institutions to facilitate the development of a similar tool within their own EMR platform. For example, the provided screenshots and detailed descriptions of data categories, fields, and choices may provide all of the information needed to recreate the tool within another EMR platform without additional content or explanation from the neurosurgeon. For those institutions using the Epic EMR system, our configuration can be shared electronically without cost. Ideally, a uniform configuration, possibly guided by organized pediatric neurosurgery and/or research groups such as the Hydrocephalus Clinical Research Network, would offer an equivalent set of tools to each neurosurgeon and allow collection of standardized data during routine patient care. Such consistency and user demand may then entice and enable all EMR vendors to incorporate this functionality into their existing software system without requiring each institution to do this work independently.

If the dearth of published literature is an indication, neurosurgery is only in the early stages of harnessing the power of EMR technology. As time progresses, collaboration with health information technology professionals may yield burgeoning clinical, QI, and research opportunities. Thus far, only a few articles have discussed the potential. ${ }^{3,4,6-8}$ Some systems are focused on clinical decision support and require data entry separate from routine clinical use. ${ }^{3}$ Some reports rely on routine EMR data and must be supplemented with review of non-EMR data. ${ }^{6}$ Other reports are based on prospectively created EMR outcome fields in addition to standard ones. ${ }^{8}$ Large multiinstitutional registries, such as the Quality Outcomes Database (formerly known as the National Neurosurgery Quality and Outcomes Database) ${ }^{4}$ require personnel for EMR data extraction and then centralized data entry. Others, such as the Hydrocephalus Clinical Research Network, rely on data collection in parallel with the EMR. Ideally, EMR modules for disease-specific structured data capture would simplify and augment routine clinical practices while compiling prospective institutional data with automatic upload into centralized multiinstitutional registries for QI and research use. ${ }^{7}$ We feel that the tool we created may be used as a CSF shunt module in that schema.

\section{Conclusions}

We report our development of an electronic tool for CSF shunt history built as part of the patient's existing electronic health record. It has potential benefit in the clinical, QI, and research arenas. We have endeavored to describe it in a manner that would allow an interested neurosurgeon to share this publication with health information technology professionals to facilitate the development of a similar tool within their institution's own EMR platform.

\section{References}

1. Blumenthal D, Tavenner M: The "meaningful use" regulation for electronic health records. N Engl J Med 363:501-504, 2010

2. Centers for Medicare and Medicaid Services: Electronic health records (EHR) incentive programs. CMS.gov (https:// www.cms.gov/Regulations-and-Guidance/Legislation/ EHRIncentivePrograms/index.html) [Accessed January 4, 2017]

3. Dimopoulos KG, Baltogiannis C, Scorila E, Kimonides VG, Sakas D, Lymberopoulos DK: DESSA: a new decision support system for neurosurgery. Conf Proc IEEE Eng Med Biol Soc 5:3416-3419, 2004

4. McGirt MJ, Speroff T, Dittus RS, Harrell FE Jr, Asher AL: The National Neurosurgery Quality and Outcomes Database $\left(\mathrm{N}^{2} \mathrm{QOD}\right)$ : general overview and pilot-year project description. Neurosurg Focus 34(1):E6, 2013

5. Office of the National Coordinator for Health Information Technology: HER incentives \& certification. Meaningful use definition \& objectives. HealthIT.gov (https://www.healthit. gov/providers-professionals/meaningful-use-definitionobjectives) [Accessed January 4, 2017]

6. Patil V, Lacson R, Vosburgh KG, Wong JM, Prevedello L, Andriole K, et al: Factors associated with external ventricular drain placement accuracy: data from an electronic health record repository. Acta Neurochir (Wien) 155:1773-1779, 2013

7. Pittman CA, Miranpuri AS: Neurosurgery clinical registry data collection utilizing Informatics for Integrating Biology and the Bedside and electronic health records at the University of Rochester. Neurosurg Focus 39(6):E16, 2015

8. Theodosopoulos PV, Ringer AJ, McPherson CM, Warnick RE, Kuntz C IV, Zuccarello M, et al: Measuring surgical outcomes in neurosurgery: implementation, analysis, and auditing a prospective series of more than 5000 procedures. J Neurosurg 117:947-954, 2012

9. Zusman EE: Meeting meaningful use objectives for Electronic Health Record implementation. Neurosurgery 69:N24N26, 2011

\section{Disclosures}

The authors report no conflict of interest concerning the materials or methods used in this study or the findings specified in this paper.

\section{Author Contributions}

Conception and design: both authors. Acquisition of data: both authors. Analysis and interpretation of data: both authors. Drafting the article: Governale. Critically revising the article: both authors. Reviewed submitted version of manuscript: both authors. Approved the final version of the manuscript on behalf of both authors: Governale. Study supervision: Governale.

\section{Supplemental Information \\ Online-Only Content}

Supplemental material is available with the online version of the article.

Appendix 1. https://thejns.org/doi/suppl/10.3171/2016.11. PEDS16381.

\section{Correspondence}

Lance S. Governale, Division of Pediatric Neurosurgery, Nationwide Children's Hospital, 700 Children's Dr., Columbus, OH 43205. email: lance.governale@nationwidechildrens.org. 